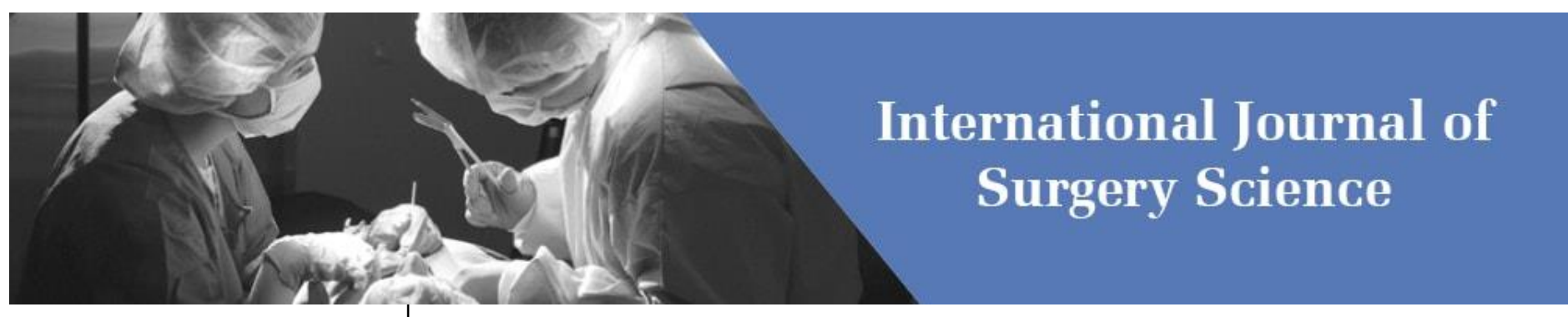

E-ISSN: 2616-3470

P-ISSN: 2616-3462

(C) Surgery Science

www.surgeryscience.com

$2021 ; 5(3): 90-93$

Received: 15-05-2021

Accepted: 17-06-2021

Dr. Singhvi Inderchand

Associate Professor, Department of General Surgery, Navodaya

Medical College and Research

Centre, Raichur, Karnataka, India

Dr. Avinash Kulkarni

Assistant Professor, Department of

General Surgery, Navodaya

Medical College and Research

Centre, Raichur, Karnataka, India

Corresponding Author:

Dr. Avinash Kulkarni

Assistant Professor, Department of

General Surgery, Navodaya

Medical College and Research

Centre, Raichur, Karnataka, India

\section{Clinical profile of patients on prophylactic parenteral antibiotics with combined parenteral and pre-operative intra-incisional antibiotic administration in reducing surgical site infection}

\section{Dr. Singhvi Inderchand and Dr. Avinash Kulkarni}

DOI: $\underline{\text { https://doi.org/10.33545/surgery.2021.v5.i3b.743 }}$

\section{Abstract}

A number of observations by nineteenth-century physicians and investigators were critical to our current understanding of the pathogenesis, prevention, and treatment of surgical infections. In 1846, Ignaz Semmelweis, a Magyar physician, took a post at the Allgemein Krankenhaus in Vienna. He noticed that the mortality from puerperal ("childbed") fever was much higher in the teaching ward (1:11) than in the ward where patients were delivered by midwives (1:29). The patients were divided into two groups: Group A: Prophylaxis by systemic (intravenous) infiltration of the antibiotic. Group B: Prophylaxis by both systemic (intravenous) and intra-incisional infiltration of the antibiotic. The first patient was allocated to group A. The second patient to group B, the third one to group A and so on so forth till we achieved our desired number of subjects in both the groups. In Group 1, duration of surgery of $>1 \mathrm{hr}$ were $3(5 \%)$, same as in group 2 . The percentage duration of surgery $>1 \mathrm{hr}$ and $<1 \mathrm{hr}$ of in both the groups were Equal.(P=1.000). In Group 1, the mean preoperative TLC was $6838.00 \pm 1700.00$ and in Group 2 it was 7126.00 \pm 1815.00 . The mean preoperative TLC was comparable between the two groups $(P>0.05)$.

Keywords: Surgical site infection, clinical profile, antibiotic administration

\section{Introduction}

Surgical infection, particularly surgical site infection (SSI), has always been a major complication of surgery and trauma and has been documented for $4000-5000$ years ${ }^{[1]}$.

A number of observations by nineteenth-century physicians and investigators were critical to our current understanding of the pathogenesis, prevention, and treatment of surgical infections. In 1846, Ignaz Semmelweis, a Magyar physician, took a post at the Allgemein Krankenhaus in Vienna. He noticed that the mortality from puerperal ("childbed") fever was much higher in the teaching ward $(1: 11)$ than in the ward where patients were delivered by midwives $(1: 29)$. He also made the interesting observation that woman who delivered before arrival on the teaching ward had a negligible mortality rate. He then hypothesized that puerperal fever was caused by putrid material transmitted from patients dying of this disease by carriage on the examining fingers of the medical students and physicians who frequently went from the autopsy room to the wards. The low mortality noted in the midwives ward, Semmelweis realized, was due to the fact that midwives did not participate in autopsies. Fired with the zeal of his revelation, he posted a notice on the door to the ward requiring all caregivers to rinse their hands thoroughly in chlorine water before entering the area ${ }^{[2]}$. This simple intervention reduced mortality from puerperal fever to $1.5 \%$, surpassing the record of the midwives. In 1861, he published his classic work on childbed fever based on records from his practice ${ }^{[3]}$

Unfortunately, Semmelweis' ideas were not well accepted by the authorities of the time.

Louis Pasteur performed a body of work during the latter part of the nineteenth century that provided the underpinnings of modern microbiology, at the time known as germ theory. His work in humans followed experiments identifying infectious agents in silkworms. He was able to elucidate the principle that contagious diseases are caused by specific microbes and that these microbes are foreign to the infected organism. Using this principle, he developed techniques of sterilization critical to oenology and identified several bacteria responsible for human illnesses, including Staphylococcus, Streptococcus, and pneumococcus ${ }^{[4]}$. 
Joseph Lister, the son of a wine merchant, was appointed professor of surgery at the Glasgow Royal Infirmary in 1859. In his early practice, he noted that more than $50 \%$ of his patients undergoing amputation died due to postoperative infection. After hearing of Pasteur's theory, Lister experimented with the use of a solution of carbolic acid, which he knew was being used to treat sewage. He first reported his findings to the British Medical Association in 1867 using dressings saturated with carbolic acid on 12 patients with compound fractures; 10 recovered without amputation, one survived with amputation, and one died of causes unrelated to the wound. In spite of initial resistance, his methods were quickly adopted throughout Europe $[5,6]$.

\section{Methodology \\ Study design}

The Present study was a prospective, descriptive, comparative, case series study

\section{Study population}

All patients admitted to department of general surgery.

\section{Sample size and sampling technique}

Dogra et al. in their study reported a proportional difference of surgical site infection between the two groups to be $15.5 \%$.Based on this proportional difference we have calculated our sample size. Sample size calculation revealed that 57 patients per group will be required to detect a proportional difference of $15.5 \%$ between two groups, at an alpha of 0.05 with power of $80 \%$.

$\mathrm{P}$ values $<0.05$ were considered to indicate statistical significance. Hence, we took 60 patients per group.

\section{Formula}

This calculator uses the following formula for the sample size $\mathrm{n}$ : $\mathrm{n}=\left(\mathrm{Z}_{\alpha / 2}+\mathrm{Z}_{\beta}\right)^{2} *\left(\mathrm{p}_{1}\left(1-\mathrm{p}_{1}\right)+\mathrm{p}_{2}\left(1-\mathrm{p}_{2}\right)\right) /\left(\mathrm{p}_{1}-\mathrm{p}_{2}\right)^{2}$, where $\mathrm{Z}_{\alpha / 2}$ is the critical value of the Normal distribution at $\alpha / 2$ (e.g. for a confidence level of $95 \%, \alpha$ is 0.05 and the critical value is 1.96), $\mathrm{Z}_{\beta}$ is the critical value of the Normal distribution at $\beta$ (e.g. for a power of $80 \%, \beta$ is 0.2 and the critical value is 0.84 ) and $\mathrm{p}_{1}$ and $\mathrm{p}_{2}$ are the expected sample proportions of the two groups.

\section{Grouping}

The patients were divided into two groups:

Group A: Prophylaxis by systemic (intravenous) infiltration of the antibiotic.

Group B: Prophylaxis by both systemic (intravenous) and intraincisional infiltration of the antibiotic.

The first patient was allocated to group A. The second patient to group B, the third one to group $\mathrm{A}$ and so on so forth till we achieved our desired number of subjects in both the groups.

\section{Inclusion criteria}

1. Patients in age group of $25-65$ years

2. Patients of either gender

3. Procedures that lasted for less than 2 hours clean and clean contaminated surgical procedures

4. Patient and/or his/her legally acceptable representative willing to provide their voluntary written informed consent for participation in the study.

\section{Exclusion criteria}

1. Patients with Diabetes mellitus, immunocompromised and those on steroid therapy.

2. Patient and/or his/her legally acceptable representative not willing to provide their voluntary written informed consent for participation in the study.

3. Pregnant women.

4. Patients with bleeding disorders and on anticoagulant treatment.

5. Antibiotics related complications (known hypersensitivity)

\section{Results}

Table 1: Distribution according to age

\begin{tabular}{|c|c|c|c|c|}
\hline \multirow{2}{*}{ Age } & \multicolumn{2}{|c|}{ Group 1 (n=60) } & \multicolumn{2}{c|}{ Group 2 (n=60) } \\
\cline { 2 - 5 } & No. & \% & No. & \% \\
\hline 31-40 years & 6 & 10.0 & 6 & 10.0 \\
\hline 41-50 years & 31 & 51.7 & 23 & 38.3 \\
\hline 51-60 years & 23 & 38.3 & 28 & 46.7 \\
\hline 61-70 years & 0 & 0.0 & 3 & 5.0 \\
\hline Total & 60 & 100.0 & 60 & 100.0 \\
\hline Mean + SD (years) & $48.75 \pm 6.11$ & $50.43 \pm 6.68$ \\
\hline 't' Value & \multicolumn{5}{|c|}{$0.14, \mathrm{df}=118$} \\
\hline P Value & \multicolumn{5}{|c|}{$0.155, \mathrm{NS}$} \\
\hline
\end{tabular}

Unpaired ' $\mathrm{t}$ ' test applied. $\mathrm{P}=0.155$, Not significant

The above table shows the distribution of patients of both the groups according to age.

In Group 1, majority of the patients $31(51.7 \%)$ were in the age group $41-50$ years, while $23(38.3 \%)$ patients were in the age group 51-60 years.

In Group 2, majority of the patients $28(46.7 \%)$ were in the age group 51-60 years, while $23(38.3 \%)$ patients were in the age group 41-50 years.

The mean age in Group 1 was $48.75 \pm 6.11$ years, while in Group 2 it was $50.43 \pm 6.68$ years. The difference was found to be statistically not significant $(P>0.05)$, showing that the two groups were comparable with respect to age.

Table 2: Comparison of ASA score

\begin{tabular}{|c|c|c|c|c|}
\hline \multirow{2}{*}{ ASA score } & \multicolumn{2}{|c|}{ Group 1 (n=60) } & \multicolumn{2}{c|}{ Group 2 (n=60) } \\
\cline { 2 - 5 } & No. & \% & No. & \% \\
\hline 1 & 20 & 33.33 & 26 & 43.33 \\
\hline 2 & 40 & 66.67 & 34 & 56.67 \\
\hline Total & 60 & 100.0 & 60 & 100.0 \\
\hline
\end{tabular}

Pearson Chi-Square $=1.269, \mathrm{DF}=1, \mathrm{P}-$ Value $=0.260$

Fisher's exact test: $\mathrm{P}-$ Value $=0.347916$

The above table shows the comparison of \% ASA score difference in both the groups.

Total \%ASA score 1 in Group 1 was 33.33, in Group 2 was 66.67. Total \%ASA score 2 in Group 2 was 43.33, in Group 2 was 56.67. The \%ASA score 1 and 2 in both the groups were comparable $(P>0.05)$.

Table 3: Distribution according to gender

\begin{tabular}{|c|c|c|c|c|}
\hline \multirow{2}{*}{ Gender } & \multicolumn{2}{|c|}{ Group 1 (n=60) } & \multicolumn{2}{c|}{ Group 2 (n=60) } \\
\cline { 2 - 5 } & No. & \% & No. & \% \\
\hline Female & 13 & 21.7 & 16 & 26.7 \\
\hline Male & 47 & 78.3 & 44 & 73.3 \\
\hline Total & 60 & 100.0 & 60 & 100.0 \\
\hline
\end{tabular}

$\chi 2=0.409, \mathrm{df}=1, \mathrm{P}$ value $=0.522$, Not significant

The above table shows the distribution of patients of both the groups according to gender.

In Group 1, $13(21.7 \%)$ patients were females and $47(78.3 \%)$ 
patients were males.

In Group 2, 16 (26.7\%) patients were females and 44 (73.3\%) patients were males.

In both the groups, there was a male preponderance in relation to the females.

There was a proportional similarity in both the genders between the two groups $(P>0.05)$.

Male SSI was higher in Group 1 in comparison to Female, but we could not find the statistical significance as there was only 1 patient in Group 2.

Table 4: Comparison of duration

\begin{tabular}{|c|c|c|c|c|}
\hline \multirow{2}{*}{ Time taken } & \multicolumn{2}{|c|}{ Group 1 (n=60) } & \multicolumn{2}{c|}{ Group 2 (n=60) } \\
\cline { 2 - 5 } & No. & \% & No. & \% \\
\hline$<1 \mathrm{hr}$ & 57 & 95 & 57 & 95 \\
\hline$>1 \mathrm{hr}$ & 3 & 5 & 3 & 5 \\
\hline Total & 60 & 100.0 & 60 & 100.0 \\
\hline
\end{tabular}

Pearson Chi-Square $=0.000, \mathrm{DF}=1, \mathrm{P}-$ Value $=1.000$

The above table shows the comparison of duration of surgery in both the groups.

In Group 1, duration of surgery of $>1 \mathrm{hr}$ were $3(5 \%)$, same as in group 2. The percentage duration of surgery $>1 \mathrm{hr}$ and $<1 \mathrm{hr}$ of in both the groups were Equal. $(\mathrm{P}=1.000)$

Table 5: Comparison of mean preoperative TLC

\begin{tabular}{|c|c|c|}
\hline TLC & $\begin{array}{c}\text { Group 1 (n=60) } \\
{[\text { Mean } \pm \text { SD] }}\end{array}$ & $\begin{array}{c}\text { Group 2 }(\mathbf{n}=60) \\
{[\text { Mean } \pm \text { SD] }}\end{array}$ \\
\hline Mean \pm SD $($ per cumm) & $6838.00 \pm 1700.00$ & $7126.00 \pm 1815.00$ \\
\hline 't' Value & \multicolumn{2}{|c|}{$-0.90, \mathrm{df}=118$} \\
\hline P Value & \multicolumn{2}{|c|}{$0.372, \mathrm{NS}$} \\
\hline
\end{tabular}

Unpaired ' $\mathrm{t}$ ' test applied. $\mathrm{P}=0.372$, Not significant

The above table shows the comparison of mean preoperative TLC in both the groups.

In Group 1, the mean preoperative TLC was $6838.00 \pm 1700.00$ and in Group 2 it was $7126.00 \pm 1815.00$.

The mean preoperative TLC was comparable between the two groups $(P>0.05)$.

Table 6: Comparison of mean cost of treatment

\begin{tabular}{|c|c|c|}
\hline Cost of Treatment (Rs.) & $\begin{array}{c}\text { Group 1 (n=60) } \\
{[\text { Mean } \pm \text { SD] }}\end{array}$ & $\begin{array}{c}\text { Group 2 }(\mathbf{n}=60) \\
{[\text { Mean } \pm \text { SD] }}\end{array}$ \\
\hline Mean \pm SD (Rs.) & $22950.00 \pm 2500.00$ & $22017.00 \pm 1621.00$ \\
\hline ' $t$ ' Value & \multicolumn{2}{|c|}{$2.43, \mathrm{df}=118$} \\
\hline P Value & \multicolumn{2}{|c|}{$0.017^{*}$} \\
\hline
\end{tabular}

Unpaired ' $\mathrm{t}$ ' test applied. $\mathrm{P}=0.017$, Significant

The above table shows the comparison of mean cost of treatment in both the groups.

In Group 1, the mean cost of treatment was Rs. $22950.00 \pm$ 2500.00, while in Group 2 it was $22017.00 \pm 1621.00$.

There was a significantly higher expense in Group 1 in comparison to Group $2(P<0.05)$.

\section{Discussion}

In our study in Group 1, majority of the patients $31(51.7 \%)$ were in the age group 41-50 years, while $23(38.3 \%)$ patients were in the age group 51-60 years. In Group 2, majority of the patients $28(46.7 \%)$ were in the age group 51-60 years, while 23 (38.3\%) patients were in the age group 41-50 years. The mean age in Group 1 was $48.75 \pm 6.11$ years, while in Group 2 it was $50.43 \pm 6.68$ years. The difference was found to be statistically not significant $(P>0.05)$, showing that the two groups were comparable with respect to age. As Kaye et al. ${ }^{[7]}$ revealed a significant relationship between age and risk of SSI $(\mathrm{P}=.006)$. Risk of SSI increased by $1.1 \%$ year between ages 17 and 65 years $(\mathrm{P}=.002)$. At age $\geqslant 65$ years, risk of SSI decreased by $1.2 \%$ for each additional year $(\mathrm{P}=.008)$. Sangrasi et al. ${ }^{[8]}$ considered increasing age as a significant risk factor for increased surgical site infection $(P<0.05)$. Neumayer et al. ${ }^{[9]}$ found that Patients aged over 40 had a statistically significantly increased risk of developing SSI compared with those under 40 years (OR 1.24, 95\% CI 1.07 to 1.44 )

In our study total \%ASA score 1 in Group 1 was 33.33, in Group 2 was 66.67.Total \%ASA score 2 in Group 2 was 43.33, in Group 2 was 56.67. The \%ASA score 1 and 2 in both the groups were comparable $(P>0.05)$. As Chattopadhyay et al. ${ }^{[10]}$ found that there were significantly higher SSI and nosocomial infection rates among patients with combined American Society of Anesthesiologists (ASA) scores II and III than those with ASA score $I$ in contaminted or dirty wounds (chi2 $=5.06$ and chi2 $=6.34$ respectively). Khan et al. ${ }^{[11]}$ found that there were significantly higher surgical site infection rates among patients with combined ASA score II and III than those with ASA score I in clean contaminated $(\mathrm{p}=0.0007)$, and dirty cases $(\mathrm{p}=0.0212)$. Ridgeway et al. ${ }^{[12]}$ conducted a study in which they found, In the single variable analysis of THRs, American Society of Anesthesiologists (ASA) score was significantly associated with the risk of SSI $(P<0.05)$.similar results were found with hemiarthroplasty and revision THRs. Also the multivariate analysis identified ASA score as significant, independent risk factors for SSI.

In our study in Group 1, the mean BMI level was $21.38 \pm 1.68$ $\mathrm{kg} / \mathrm{m}^{2}$, while in Group 2 it was $21.18 \pm 1.64 \mathrm{~kg} / \mathrm{m}^{2}$. The mean BMI in both the groups were comparable $(P>0.05)$. As Waisbren et al. ${ }^{[13]}$ found that in univariate analyses, one of the significant predictors of SSI was percent body fat $(\% \mathrm{BF}) \mathrm{p}=$ 0.005 and in multivariable analysis, obese patients by $\% \mathrm{BF}$ had a 5-fold higher risk for SSI than nonobese patients (odds ratio = 5.3; 95\% CI, 1.2-23.1; $\mathrm{p}=0.03$ ). Linear regression was used to show that there is a positive, nonlinear relationship between $\% \mathrm{BF}$ and BMI. Tserenpuntsag et al. ${ }^{[14]}$ found in a multivariable analysis that SSI following colon procedure was associated with body mass index greater than 30 (odds ratio [OR], 1.48 [95\% confidence interval (CI), 1.21-1.80]) Lynch et al. ${ }^{[15]}$ studied that multivariate analysis revealed BMI $>30$ to be independent risk factors for SSI following renal transplantation.

In our study we found that in Group 1, $13(21.7 \%)$ patients were females and $47(78.3 \%)$ patients were males. In Group 2, 16 (26.7\%) patients were females and $44(73.3 \%)$ patients were males. In both the groups, there was a male preponderance in relation to the females. There was a proportional similarity in both the genders between the two groups $(P>0.05)$.Male SSI was higher in Group 1 in comparison Females, but we could not find the statistical significance as there was only 1 patient in Group 2. Similar result was found by Razavi et al. ${ }^{[16]}$ in which majority were females and SSI is not correlated with sex ( $\mathrm{p}=$ 0.093 ). In our study we found that in Group 1, duration of surgery of $>1 \mathrm{hr}$ were $3(5 \%)$, same as in group 2 .The percentage duration of surgery $>1 \mathrm{hr}$ and $<1 \mathrm{hr}$ of in both the groups were Equal. $(\mathrm{P}=1.000)$. As Dogra et al. found that Five out of 45 cases developed SSI, when the duration of surgery was between 1 and 2 hours whereas seven out of 75 cases developed SSI, when the duration of surgery was less than 1 hour. In a multivariate analysis by Cheng et al. identified duration as independent parameter correlating with the occurrence of SSI with operative duration more than 120 minutes (OR 4.289; CI 
1.773-10.378; $\mathrm{P}=0.001)$. Also the results of multivariate analyses by Jeong et al. indicated that prolonged operation time $(P=0.002)$ is an independent risk factors for SSI after gastric surgery.

\section{Conclusion}

Total \%ASA score 1 in Group 1 was 33.33, in Group 2 was 66.67. Total \%ASA score 2 in Group 2 was 43.33, in Group 2 was 56.67. The \%ASA score 1 and 2 in both the groups were comparable $(P>0.05)$.

\section{References}

1. Richet HM, Craven PC, Brown JM, Lasker BA, Cox CD, McNeil MM et al. A cluster of Rhodococcus (Gordona) Bronchialis sternal-wound infections after coronary-artery bypass surgery. N Engl J Med 1991;324(2):104-9.

2. Mangram AJ, Horan TC, Pearson ML, Silver LC, Jarvis WR. Guideline for Prevention of Surgical Site Infection, 1999. Centers for Disease Control and Prevention (CDC) Hospital Infection Control Practices Advisory Committee. Am J Infect Control 1999;27(2):97-132,133-4discussion96.

3. Martone WJ, Nichols RL. Recognition, prevention, surveillance, and management of surgical site infections: introduction to the problem and symposium overview. Clin Infect Dis 2001;33(2):S67-8.

4. Kobayashi M, Mohri Y, Inoue Y, Okita Y, Miki C, Kusunoki M. Continuous follow-up of surgical site infections for 30 days after colorectal surgery. World J Surg 2008;32(6):1142-6.

5. Cohn SM, Giannotti G, Ong AW, Varela JE, Shatz DV, McKenney MG et al. Prospective randomized trial of two wound management strategies for dirty abdominal wounds. Ann Surg 2001;233(3):409-13.

6. Margenthaler JA, Longo WE, Virgo KS, Johnson FE, Oprian CA, Henderson WG et al. Risk factors for adverse outcomes after the surgical treatment of appendicitis in adults. Ann Surg 2003;238(1):59-66.

7. Kaye KS, Schmit K, Pieper C, Sloane R, Caughlan KF, Sexton DJ. The effect of increasing age on the risk of surgical site infection. J Infect Dis 2005;191(7):1056-62.

8. Sangrasi AK, Leghari AA, Memon A, Talpur AK, Qureshi GA, Memon JM. Surgical site infection rate and associated risk factors in elective general surgery at a public sector medical university in Pakistan. Int Wound J 2008;5(1):74-8.

9. Neumayer L, Hosokawa P, Itani K, El-Tamer M, Henderson WG, Khuri SF. Multivariable predictors of postoperative surgical site infection after general and vascular surgery: results from the patient safety in surgery study. J Am Coll Surg 2007;204(6):1178-87.

10. Chattopadhyay R, Zaroukian S, Potvin E. Surgical site infection rates at the Pontiac Health Care Centre, a rural community hospital. Can J Rural Med 2006 Winter;11(1):41-8.

11. Khan M, Khalil J, Rooh-ul-Muqim, Zarin M, Touseef Ul Hassan, Ahmed N et al. Rate and risk factors for surgical site infection at a tertiary care facility in Peshawar, Pakistan. J Ayub Med Coll Abbottabad 2011;23(1):15-8.

12. Ridgeway S, Wilson J, Charlet A, Kafatos G, Pearson A, Coello R. Infection of the surgical site after arthroplasty of the hip. J Bone Joint Surg Br 2005;87(6):844-50.

13. Waisbren E, Rosen H, Bader AM, Lipsitz SR, Rogers SO Jr, Eriksson E. Percent body fat and prediction of surgical site infection. J Am Coll Surg 2010;210(4):381-9.

14. Tserenpuntsag B, Haley V, Van Antwerpen C, Doughty D,
Gase KA, Hazamy PA et al. Surgical site infection risk factors identified for patients undergoing colon procedures, New York State 2009-2010. Infect Control Hosp Epidemiol 2014;35(8):1006-12.

15. Lynch RJ, Ranney DN, Shijie C, Lee DS, Samala N, Englesbe MJ. Obesity, surgical site infection, and outcome following renal transplantation. Ann Surg 2009;250(6):1014-20.

16. Razavi SM, Ibrahimpoor M, Sabouri Kashani A, Jafarian A. Abdominal surgical site infections: incidence and risk factors at an Iranian teaching hospital. BMC Surg 2005;27(5):2. 